\title{
ARTICLE OPEN Atlantic Niño modulation of the Indian summer monsoon through Asian jet
}

\author{
Ramesh Kumar Yadav ${ }^{1}$, G. Srinivas ${ }^{1,2}$ and Jasti S. Chowdary ${ }^{1}$
}

The Indian rainfall and the Atlantic Niño peaks during summer month and have inverse relationship. This relationship has been revisited in the current study and it is found that the Atlantic Niño significantly influences a dipole pattern of rainfall in the north-east and the north-western parts of India. The positive phase of the Atlantic Niño intensifies the inter-tropical convergence zone, as a result of this local tropospheric warming, over the equatorial east Atlantic and west Africa, owing to the enlargement of the upper-troposphere divergence. This provokes meridional stationary wave owing to the stronger meridional transfer of energy, as the influences of background jet-streams are minimal over North Africa and Europe. This results in the consecutive anomalous negative, positive, and negative geopotential heights (GPHs) over the tropical east Atlantic, Mediterranean, and north-west Europe, respectively. The north-west Europe acts as the center of action for the propagation of a Rossby wave train zonally oriented toward central Asia reinforcing positive GPH anomaly over there. The positive GPH anomaly reduces the Asian subtropical westerly jetstream east of the Caspian Sea, owing to the reduction in the upper-troposphere divergence toward the Indian subcontinent and caused for above (below) normal north-east (north-west) Indian summer monsoon rainfall. The atmospheric general circulation model captures general characteristics of wave pattern and changes in the Asian jet when correlated with Atlantic Niño with considerable skill.

npj Climate and Atmospheric Science (2018)1:23; doi:10.1038/s41612-018-0029-5

\section{INTRODUCTION}

The annual rainfall in India show two peaks: during boreal summer and winter. The summer peak, which is called Indian summer monsoon (ISM), is much higher than its winter counterpart. The ISM, which is part of the south Asian monsoon system, has significant temporal and spatial variations. ${ }^{1}$ It is one of the largest global phenomena of the general circulation that not only affects the life of millions of Indian but has its impacts on the other parts of the global weather and climate. The ISM arrives from the south and north-east India in the late May or early June, and gradually advances northwards and westwards, respectively, reaching the north-west India by the end of June. ${ }^{2}$ In this way, the ISM covers the whole India by the end of June/early July and remains active till the end of August. It begins to retreat from the north-west India by the beginning of September and by the end of September it retreats form most part of the country. From July to August, the ISM is fully set up over the country. Moreover, July and August are the rainiest months, the average July-August (JA) rainfall is the major contributor, above $60 \%$, of the annual rainfall of India. The temporal and spatial variation of JA seasonal rainfall plays a decisive role in causing large-scale droughts and floods, seriously affecting the agriculture yields and the agrarian economy of the country. ${ }^{3}$ It also plays an important role in the water management and the economic planning of the country. Therefore, this becomes very important to study the seasonal JA rainfall variability.

The ISM is a fully coupled land-atmosphere-ocean system. It is linked with the local air-sea interactions and the remote climatic phenomena, for example, El-Niño-Southern Oscillation (ENSO), the
Indian Ocean Dipole Mode, western equatorial Pacific sea surface temperature $(\mathrm{SST})^{4}$ and the Atlantic Niño. Atlantic Niño primarily peaks at the boreal summer month, as the Indian rainfall. The Atlantic Niño is focused in the cold tongue region of the eastern tropical Atlantic and along the southwestern African coast. ${ }^{5}$ The cold and warm event of Atlantic Niño is symmetric with respect to amplitude, spatial patterns, and temporal evolution, whereas that of ENSO in the Pacific is asymmetric. ${ }^{6}$ The warmest temperature in the tropical Atlantic is, on average found in the western basin and to the north of the equator coincident with the position of the inter-tropical convergence zone (ITCZ). The wind field is dominated by the convergence of the north-easterly and south-easterly trade wind that meets at zonally oriented ITCZ north of the equator. ${ }^{7}$ The interannual variability of canonical Atlantic Niño mode is governed by feedbacks involving ocean dynamics and ocean-atmosphere interactions, ${ }^{6,8}$ referred to as the Bjerknes feedback, ${ }^{9}$ very similar to ENSO: a warm anomaly in the eastern equatorial basin, called positive phase of Atlantic Niño, results in a relaxation of the trade winds to its west, which leads to reduced upwelling and a deepening of the thermocline in the east that causes further warming, and vice-versa for cold phase. ${ }^{5,10}$ Later, this has been challenged in terms of the Bjerkness coupling strength $^{7,11}$ and overall contributions to the SST variability in the Atlantic Niño region. ${ }^{12}$ The warmer (cooler) SST in the eastern equatorial Atlantic intensifies (weakens) the ITCZ over east Atlantic and west African region. ${ }^{13-15}$ In the tropics, SST variations are important in shaping the spatial pattern of variations in convection and ITCZ, and through which the other atmospheric fields. The tropical Atlantic SST fundamentally drives the

\footnotetext{
${ }^{1}$ Indian Institute of Tropical Meteorology, Pashan, Pune 411008, India and ${ }^{2}$ Department of Meteorology and Oceanography, Andhra University, Visakhapatnam 530003 AP, India Correspondence: Ramesh Kumar Yadav (yadav@tropmet.res.in)
}

Received: 7 August 2017 Revised: 21 February 2018 Accepted: 23 February 2018

Published online: 13 August 2018 
interannual changes of the Atlantic ITCZ ${ }^{16,17}$ by the local air-sea interaction. ${ }^{18-20}$ The ITCZ is the region of intense convection and tropospheric heating. This tropospheric heating modulates the weather and climate remotely over Indian subcontinent and Pacific. ${ }^{13,21-24}$

Several studies ${ }^{21-24}$ showed that the east-equatorial Atlantic warm SST force low-level convergent flow, brings moist air, in the immediate surrounding coastal regions of Africa, and consequently causes increased rainfall there. Further, a Gill-Matsunotype quadrupole response to Atlantic Niño with a low-level anticyclone located over India weakens the ISM circulation. ${ }^{25,26}$ It can also induce changes in the Indian Ocean SST, especially along the coast of Africa and in the western Indian Ocean basin. Recent study ${ }^{13}$ suggested that, the ISM rainfall could be influenced by the eastern equatorial Atlantic SST via Eurasian waves as the atmospheric bridge. The intensified ITCZ over the Atlantic and the western Africa due to positive SST anomaly generates meridional stationary wave over North Africa and Europe. This generates anomalous positive and negative pressure over subtropics and extratropics, respectively, intensifying the climatological background steep pressure gradient with anomalous negative pressure field over north-west Europe and vice-versa for negative SST anomaly. The anomalous positive pressure on north-west Europe acts as the center of action for the propagation of a Rossby wave train to the north-west of India, intensifying the Tibetan High westward, which reinforces the outbreak of monsoon activity over India. However, mid-latitudinal pathway that connects the Atlantic Niño and ISM rainfall through Asian subtropical westerly jetstream (hereafter Asian jet) has not been explored.

The main objective of this study is to investigate additional pathways that link the Atlantic Niño and the ISM through Asian jet. This study hypothesized the mechanism by which the ITCZ modulated by the Atlantic Niño affects the upper-troposphere geopotential heights (GPHs) through the meridional stationary wave, which further modifies the central Asia GPH by the Eurasian wave. This influences the Asian jet. The strength of jet modulates the upper-troposphere divergence over north India and hence ISM rainfall. This new pathway would enable us to better understand the relation between Atlantic Niño and ISM, and would be useful to predict variations in rainfall in the north Indian region during peak monsoon season, JA 2 months, in advance.

\section{RESULTS}

\section{Association between Atlantic Niño and ISM}

Atlantic Niño and ISM peaks during boreal summer, therefore, it is important to explore the influence of the Atlantic Niño on ISM. Empirical Orthogonal Function (EOF) analysis has been performed on the linearly de-trended JA seasonal SST in the tropical Atlantic region over the domain $\left(50^{\circ} \mathrm{W}-15^{\circ} \mathrm{E}, 20^{\circ} \mathrm{S}-10^{\circ} \mathrm{N}\right)$, for the period 1979-2015. The first leading EOF (EOF1), which accounts for $55.57 \%$ of variance represents the Atlantic Niño pattern (Fig. 1a) and the respective principal component, PC1, as an Atlantic Niño index, referred hereafter as ANPC. The EOF1 SST pattern (Fig. 1a) shows highest loading (largest positive SST anomalies) over south of eastern equatorial Atlantic. The correlation coefficient (CC) between ANPC and high-resolution India Meteorological Department (IMD) rainfall (Fig. 1b) shows significant positive CC over north-east and east Peninsular India and significant negative CC over north-west India, central India, and Western Ghats.

The CC of ANPC with SST and the regression of $850 \mathrm{hPa}$ wind on to ANPC (Fig. 1c) show very high positive SST CC over Atlantic Niño region and simultaneous La Niña-like pattern over the Pacific. The significant negative SST anomalies in equatorial Pacific are comparable to the positive SST anomalies of the east-equatorial Atlantic. The CC between ANPC and Nino-3.4 index during JA is 0.48 , significant at $99 \%$ level, indicating the simultaneous occurrence of these phenomena. The CC over the tropical south Atlantic SST delineate the dipole-like structure with warm anomalies in the equatorial and south equatorial Atlantic, and cold anomalies in the extratropical south Atlantic, known as south Atlantic Ocean dipole. ${ }^{27}$ The $850 \mathrm{hPa}$ wind shows westerly wind anomalies over the western equatorial Atlantic. This indicates anomaly patterns are similar to the canonical Atlantic Niño event in which the relaxation of trade wind along the equator results in weak upwelling over west coast of Africa is associated with deepening of the thermocline that leads to warming of SST in the eastern equatorial Atlantic. The anomalous positive rainfall observed over the southern peninsular India (Fig. 1b) is mainly associated with western equatorial Pacific warming and central Pacific cooling, as observed during La Niña event (Fig. 1c). Strong easterly wind anomalies over the southern peninsular India from central Pacific via warm western Pacific transport moisture and lead to positive rainfall anomalies in the former region. Further, in response to anomalous warming over the equatorial western Pacific, a weak cyclonic circulation over the southern tip of India as a part of the Matsuno-Gill ${ }^{25,26}$ pattern supports enhanced rainfall locally.

Recalling the simultaneous occurrence of Atlantic Niño and negative phase of ENSO, we have used the partial correlation technique to remove the possible co-variability of ENSO from the contemporaneous ANPC on ISM (gridded IMD) rainfall (Fig. 1d) and vice-versa (Fig. 1e). ENSO is represented here as Niño-3.4 index (defined as an area averaged of SST anomalies in the region $170^{\circ} \mathrm{W}-120^{\circ} \mathrm{E} ; 5^{\circ} \mathrm{S}-5^{\circ} \mathrm{N}$ ). The partial correlation rainfall with ANPC (Fig. 1d) depicts significant dipole CC rainfall pattern in north India with positive CC at north-east India and negative CC over north-west India when ENSO is removed. Of note, no significant $\mathrm{CC}$ is observed over peninsular India unlike in Fig. 1b, whereas the partial correlation rainfall pattern of Nino-3.4 and IMD rainfall (Fig. 1e) shows significant positive CC over east India and negative CC over north India and Peninsular India when ANPC co-variability is removed. Here it is important to note that the peninsular India rainfall is mostly affected by ENSO phenomenon, whereas the north-east India and north-west India zonal dipole rainfall pattern is mostly affected by Atlantic Niño.

The CC between ANPC and GPCP rainfall (Fig. 2a) shows significant positive CC over north of equatorial Atlantic and equatorial west Africa, and negative CC over the south-east of the equatorial Atlantic. This clearly shows that the positive Atlantic Niño intensifies the ITCZ over east Atlantic and west Africa. ${ }^{13-15}$ The CC between ANPC and 200 hPa GPH (Fig. 2b) show significant positive CC over eastern Mediterranean Sea and central Asia, and negative CC over tropical eastern Atlantic, tropical Africa, and north-west Europe. The negative anomaly over tropical eastern Atlantic and tropical Africa, and positive anomaly over eastern Mediterranean infers the poleward shift of upper-troposphere GPH over north Africa. The enhancement of tropical heat source owing to the intensification of the ITCZ over east Atlantic and west Africa, intensifies the upper-troposphere outflow/divergence, which in turn pushes the upper-troposphere GPH poleward over north Africa. The successive meridional negative, positive, and negative GPH anomalies from the tropics to extratropics located over the equatorial Africa, Mediterranean, and north-west Europe, respectively, clearly resembles the stationary wave owing to the intensification of the upper-troposphere outflow/divergence over tropical Atlantic/Africa. The meridional transfer of energy is stronger between equatorial Africa and north-west Europe, as the influence of the background jet-streams is minimal over this region. ${ }^{13}$ The Rossby wave activity flux ${ }^{28}$ (Fig. 2a, black arrows) shows preferred region for the propagation of strong Rossby wave train zonally oriented from the north Atlantic towards the central Asia via north-west Europe. The negative GPH anomaly formed over north-west Europe owing to the Atlantic Niño warming had 

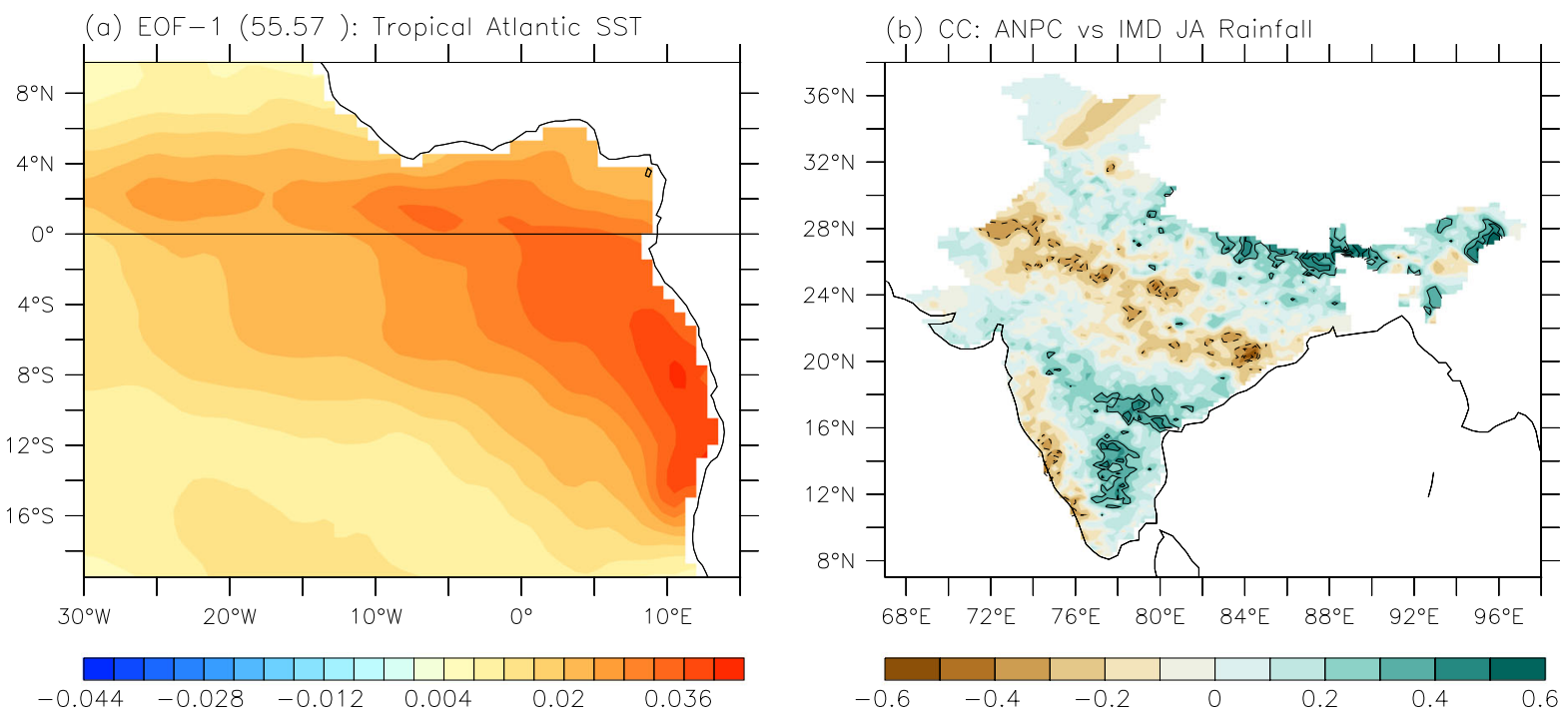

(c) CC: ANPC VS SST \& Reg: 850-hPa wind onto ANPC
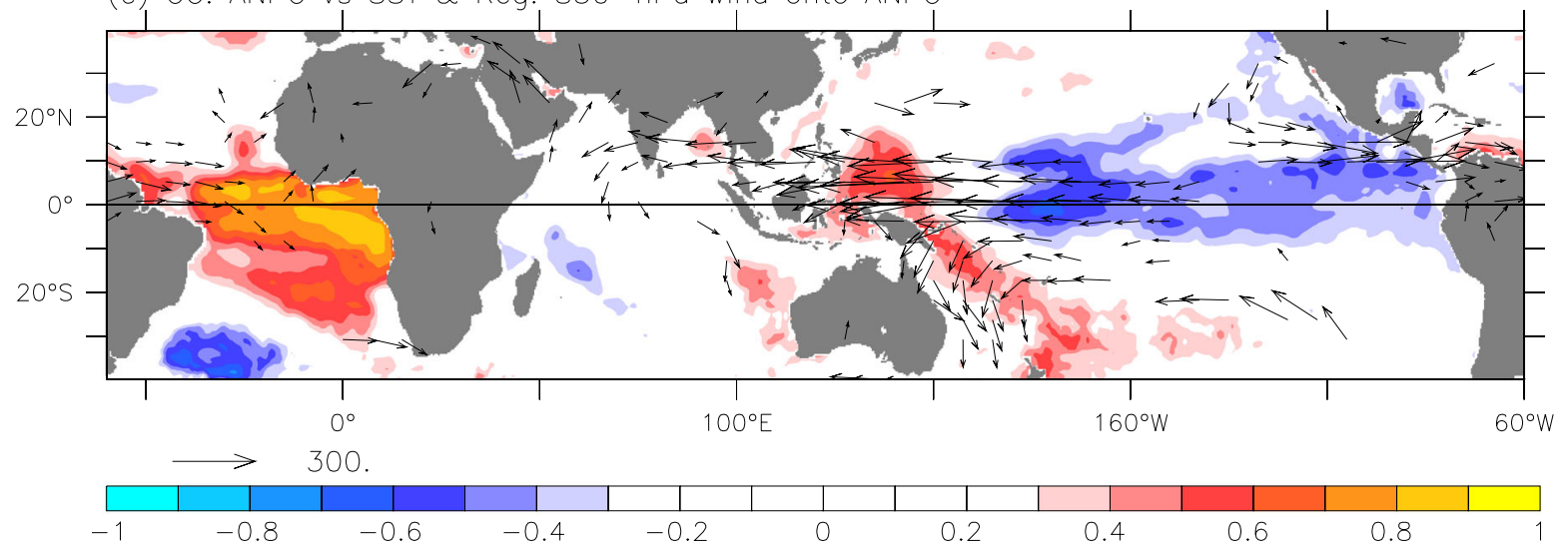

(d) PCC: ANPC vs IMD with Nino -3.4 removed

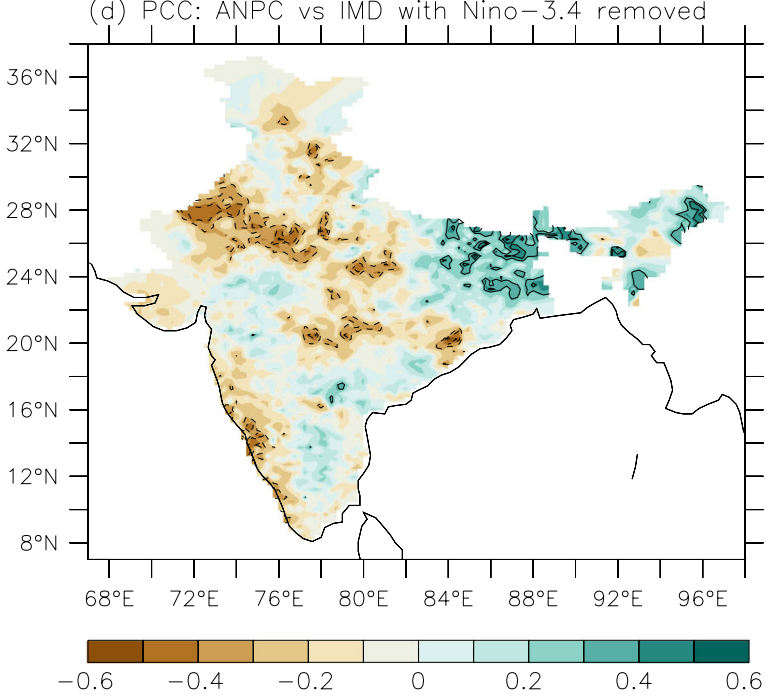

(e) PCC: Nino-3.4 vs IMD with ANPC removed

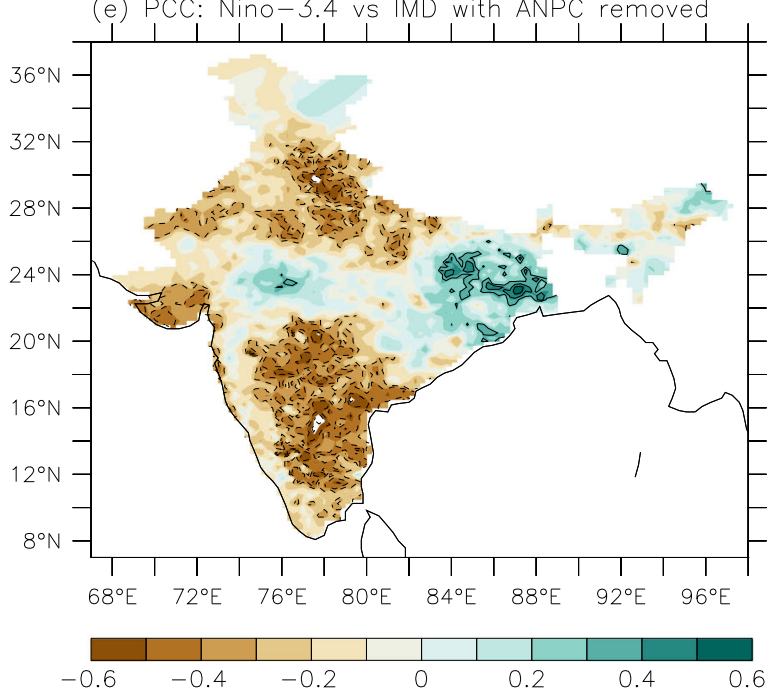

Fig. 1 a The first mode of Empirical orthogonal function (EOF1) of SST anomalies $\left({ }^{\circ} \mathrm{C}\right.$; shaded) over the equatorial Atlantic region. b Correlation between ANPC and IMD rainfall during JA. c ANPC correlation with tropical SST anomalies (shaded) and regression of ANPC upon 850-hPa winds (vectors, $\mathrm{m} / \mathrm{s}$ ). Partial correlation of $\mathbf{d}$ ANPC with IMD rainfall anomalies by removing the influence of Nino-3.4 index and e Nino-3.4 index with IMD rainfall anomalies by removing the influence of ANPC. Contours and vectors indicate the significance at $95 \%$ confidence level 



Fig. 2 Correlation of ANPC with a rainfall over the Atlantic region (shaded) and superimposed by the precipitation climatology (ITCZ, contour; $\mathrm{mm} /$ day), b $200 \mathrm{hPa}$ geopotential height (GPH) anomalies (shaded) and superimposed by GPH climatology (contours, $\mathrm{m}$ ) and c $200 \mathrm{hPa}$ zonal wind component (shaded) and superimposed by zonal wind climatology (contour, m/s) for JA. Black arrows indicate $200 \mathrm{hPa}$ horizontal component of wave activity flux climatology in both b, c. Angle grid stippling indicates the signals are significant at $95 \%$ confidence level

imposed positive GPH anomaly at central Asia by this Eurasian Rossby wave-train dispersion.

The CC pattern of $200 \mathrm{hPa}$ zonal wind (Fig. 2c) show significant easterly anomalies over equatorial Atlantic, north Africa, and north-east of Caspian Sea. In the deep tropics, the atmospheric response is baroclinic with wind anomalies being out-of-phase in the lower and upper troposphere. Therefore, easterly anomaly at equatorial Atlantic along with the weaker trade wind indicates the weak zonal Atlantic Walker circulation. The easterly anomaly over north Africa and east of Caspian Sea refers the weakening of the Asian jet at its entrance over north Africa and east of Caspian Sea. The weakening of the Asian jet is owing to the observed positive GPH anomalies toward its north over Mediterranean and central Asia. The positive GPH anomaly is associated with anomalous clockwise circulation and easterly anomaly to the south of its center in the Northern Hemisphere. In addition, these GPH anomalies have also decreased the climatological background pressure gradient between tropics and mid-latitude, responsible for the weakening of Asian jet. The region south of Asian jet is embedded with relative negative vorticities. These vorticities are formed owing to negative shear vorticities produced by the Asian jet to the south of its jet streak. The vorticity is anti-correlated with divergent. Here, weakening of Asian jet, therefore subdue the convective activity over north-west and central India and hence the ISM. The Rossby wave activity flux ${ }^{28}$ (Fig. 2b, black arrows) shows that the wave from north-west Europe also enters the Asian jet at north-east of Mediterranean, and points continuously eastward toward east Asia along the Asian jet, as this stationary Rossby wave gets trapped in the Asian jet, called "Silk Road" pattern. ${ }^{29-32}$ Overall, the warm phase of Atlantic Niño is associated with intensification of the ITCZ over the Atlantic and west Africa, negative GPH anomaly over north-west Europe, positive GPH 
anomalies over Mediterranean and central Asia, weakening of Asian jet and deficient ISM.

It is found that the Atlantic Niño is simultaneously associated with the zonal dipole rainfall pattern compromising north-east and north-western part of India during its peak rainy season (JA). Therefore, two boxes $82.5^{\circ} \mathrm{E}-91^{\circ} \mathrm{E}, 23^{\circ} \mathrm{N}-28^{\circ} \mathrm{N}$ and $71.25^{\circ} \mathrm{E}-78.5^{\circ} \mathrm{E}$, $24.5^{\circ} \mathrm{N}-28.75^{\circ} \mathrm{N}$, representing north-east and north-west India, respectively, have been considered for constructing an index by taking the difference between these two boxes, named hereafter as PSMR (peak summer monsoon rainfall) index. The simultaneous CC between this PSMR index and gridded rainfall over Indian landmass (Fig. 3a) is very similar to Fig. 3 of Kucharski and Joshi ${ }^{33}$ with reverse sign in which they have removed the possible covariability of ENSO from tropical south Atlantic index. The CC between PSMR and Nino-3.4 index is very weak $(-0.006)$, whereas the CC between PSMR and ANPC is 0.48 , significant at the $99 \%$ confidence level, confirming the robust relationship between PSMR and Atlantic Niño and independent of ENSO influence.

The CC between PSMR and the tropical SST (Fig. 3b) shows significant positive $\mathrm{CC}$ over the east and central equatorial Atlantic. The regression of $850 \mathrm{hPa}$ wind with PSMR (Fig. 3b; vectors) shows northeasterly and westerly wind anomaly over Arabian Sea and north India, representing the weak ISM circulation and weaker monsoon trough over central India, respectively. The pattern over Atlantic displays the positive phase of Atlantic Niño. It is not surprising to note that no significant correlation is observed over the Pacific/ENSO region, as the east-west dipole rainfall pattern is strongly influenced by Atlantic Niño and independent of ENSO influence.

The CC pattern between PSMR and gridded $200 \mathrm{hPa}$ GPH (Fig. 3c) show significant negative and positive zonal dipole CC over north-west Europe and central Asia, respectively. The anomalous GHP over north-west Europe acts as a center of action for the propagation/initiation of Eurasian Rossby wave train eastward towards central Asia. ${ }^{13,34,35}$ The CC pattern between PSMR and gridded $200 \mathrm{hPa}$ zonal wind (Fig. 3d) show significant negative CC zonally stretching along the slightly north of the Asian jet core, and significant negative CC zonally elongated at latitude $30^{\circ} \mathrm{N}$ between Iraq to east China indicating weakening of the Asian jet over central Asia during the excess years of PSMR and vice-versa. The GPH and zonal wind anomalies are consistent with Fig. 2. In summary, the positive phase of Atlantic Niño, the zonal dipole structure over Eurasia with negative and positive GPH anomaly over north-west Europe and central Asia, respectively, and the weaker Asian jet are unfavorable for rainfall in the north-west and central India.

The seasonality (i.e., the month-by-month standard deviation) of the PSMR (thick blue curve, Fig. 4a) and their respective two boxes over north-east India (thin red curve, Fig. 4a) and north-west India (thin green curve, Fig. 4a), and of Atlantic ElNiño index averaged over the box $\left(5^{\circ} \mathrm{W}-12^{\circ} \mathrm{E}, 8^{\circ} \mathrm{S}-3^{\circ} \mathrm{N}\right)$ during the warm years of Atlantic Niño, named hereafter as ATN (thick black curve, Fig. 4a) are carried out. The ATN standard deviation peaks during June, whereas rainfall indices peak during the months of July and August. Further, we have calculated the time-lag correlation for the JA PSMR (thick black curve, Fig. 4b) and simultaneous CC for the entire summer months from June through September (thick dashed black curve, Fig. 4b) with ATN and shown in Fig. 4b. The lag correlation peaks at zero lag during July and August. May and June are statistically significant but the CC values are less than zero lag and can be used as predictor for JA seasonal PSMR with -2 lag months. The simultaneous CC shows significant values during July and August of the summer months. These characterize the robustness of the related variability during $J A$.

The PSMR and ANPC index (Fig. 4c) shows significant year-toyear variation. The in-phase relationship between them can be observed for the years: 1982, 1983, 1992, and 1994 when PSMR was excess and the ANPC was positive, and 1984, 1987, 1988, 1998, 1999, 2007, and 2008 when the PSMR was deficient and ANPC was negative. In the years 2006 and 2010 both the indices are out-of-phase. During 2010, strong La Niña year undermine the Atlantic Niño effect. Here, it is to be noted that the inverse PSMR (-PSMR) index is different from the IMD index (Fig. 4d). The excess and deficient PSMR years may not match with the flood and drought years of IMD such as 2009 (drought year according to IMD), and 1988 and 1998 (flood years according to IMD). Earlier researchers have considered different index for ISM, such as all ISM rainfall (AIR) from IITM/IMD records, extended India summer monsoon rainfall (EIR) averaged over a box $\left(70^{\circ} \mathrm{E}-110^{\circ} \mathrm{E} ; 10^{\circ} \mathrm{N}-30^{\circ}\right.$ N) from GPCP data, ${ }^{36}$ central India summer monsoon rainfall (CIR) averaged over a box $\left(74.5^{\circ} \mathrm{E}-86.5^{\circ} \mathrm{E} ; 16.5^{\circ} \mathrm{N}-26.5^{\circ} \mathrm{N}\right)$ from IMD gridded rainfall data ${ }^{37}$ and homogeneous India summer monsoon rainfall $(\mathrm{HIR})$ averaged over a box $\left(70^{\circ} \mathrm{E}-85^{\circ} \mathrm{E} ; 10^{\circ} \mathrm{N}-30^{\circ} \mathrm{N}\right)$ from CRU data. ${ }^{23}$ The standardized time-series of these indices along with inverse PSMR index for the season JA is plotted in the Fig. $4 \mathrm{~b}$. The CC of -PSMR with AIR, HIR, CIR, and EIR are 0.33, 0.47, 0.466, and 0.226 , respectively. The CC of AIR is significant at $95 \%$ level and the HIR and CIR are significant at 99\% level. Only, EIR is not statistically significant. This suggests that the -PSMR represents the homogeneous and central India rainfall, which represents mostly the western and central India rainfall respectively. The CC values of -PSMR with different index are not near to 0.9 to be called as same and also evident from the spread observed among them in Fig. $4 b$ for most of the years.

Composite of extreme years

To study the composite of excess and deficient extreme year circulation, 9 extreme years have been identified, 5 excess years when PSMR was excess and ANPC was positive, i.e., 1984, 1987, 1988,1998 , and 1999 and four deficient years when PSMR was deficient and ANPC was negative, i.e., 1982, 1983, 1992, and 1994 (Fig. 4a). The composite of excess and deficient year of $200 \mathrm{hPa}$ horizontal component of wave activity flux ${ }^{28}$ have been shown by black arrows, zonal wind by color shade and GPH anomaly by pink contours (Fig. 5a, b, respectively). During the excess year composite (Fig. 5a), the Asian jet is weaker between the north-east Mediterranean to the east of Caspian Sea. The positive GPH anomalies over Mediterranean and central Asia, and negative anomaly at north-west Europe is quite evident. The positive GPH anomaly over central Asia is caused for weak Asian jet along the east of Caspian Sea. The successive zonal negative and positive GPH anomalies at mid-latitude/extra-tropics overlaid with wave activity flux depicts the Rossby wave train propagation over Eurasia. In contrast, the Asian jet is stronger during the deficient years, the dipole GPH anomaly with positive anomaly over north-west Europe and negative anomaly over central Asia is quite evident. The negative GPH anomaly over north-east of Mediterranean and central Asia had intensified the Asian jet from north-east of Mediterranean to the east of Caspian Sea (Fig. 5b). In both the cases, wave-train is zonally oriented over Eurasian region, propagating through north-west Europe continuously eastward toward central Asia. The Rossby wave train successively induces opposite GPH anomaly from north-west Europe to central Asia. The Rossby wave activity flux from north-west Europe also enters the Asian jet at north-east of Mediterranean, and follow the Asian jet. ${ }^{29-32}$ Overall, Fig. 5a discern that the Mediterranean and Europe GPH anomalies are subjected to the Atlantic Niño SST forcing, the central Asia GHP anomaly is subjected to the north-west Europe GPH anomaly and the mid-latitude/extratropical Eurasian Rossby wave, and the Asian jet strength towards the east of Caspian Sea is subjected to GPH anomaly at central Asia.

To show the meridional energy transfer associated with Atlantic Niño in terms of propagation of stationary wave in the upper troposphere we have plotted $200 \mathrm{hPa}$ daily $\mathrm{GPH}$ anomaly 
(a) CC: PSMR VS IMD RF

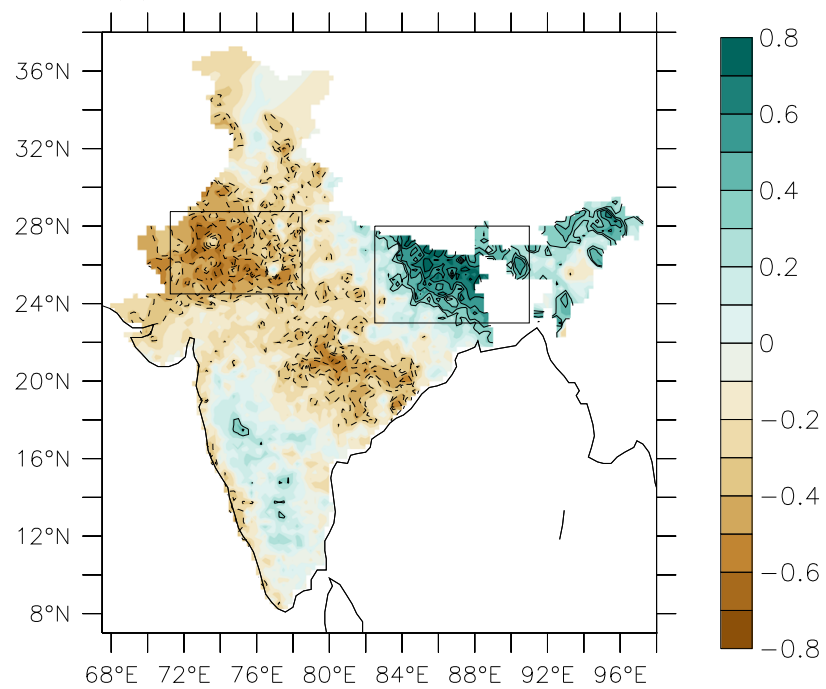

(b) CC: PSMR vs SST \& Reg: 850-hPa wind onto PSMR
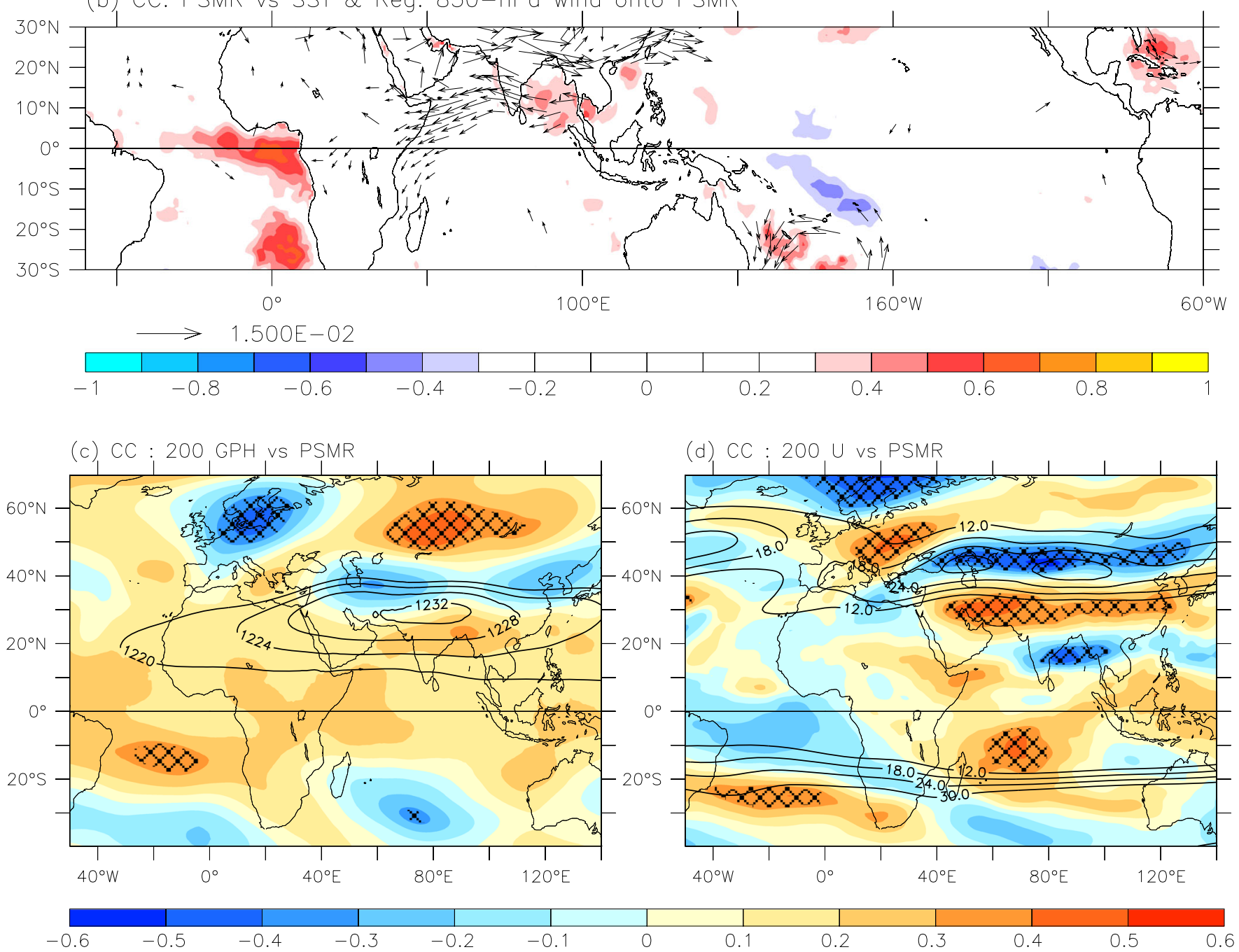

Fig. 3 The correlation of PSMR (peak summer monsoon rainfall, which is defined as difference between north-east and north-western India region rainfall anomalies during JA. It is highlighted with black boxes) with IMD rainfall (shaded), b with tropical SST anomalies (shaded) and regression of PSMR upon $850 \mathrm{hPa}$ winds (vectors; m/s), c with $200 \mathrm{hPa} \mathrm{GPH}$ anomalies (shaded) and superimposed by GPH climatology (contours, $\mathrm{m}$ ) and $\mathbf{d}$ with $200 \mathrm{hPa}$ zonal wind (shaded) and superimposed by zonal wind climatology (contour, m/s) during JA. Angle grid stippling indicates the signals are significant at $95 \%$ confidence level 
(a) Standard Deviation

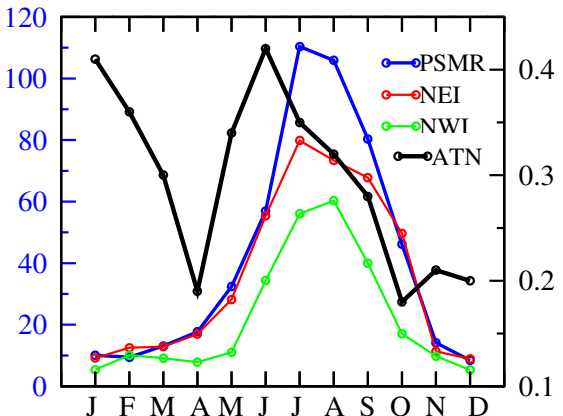

(b) Correlation Coefficent



(c) PSMR vs ANPC



(d) -PSMR vs different ISM indices

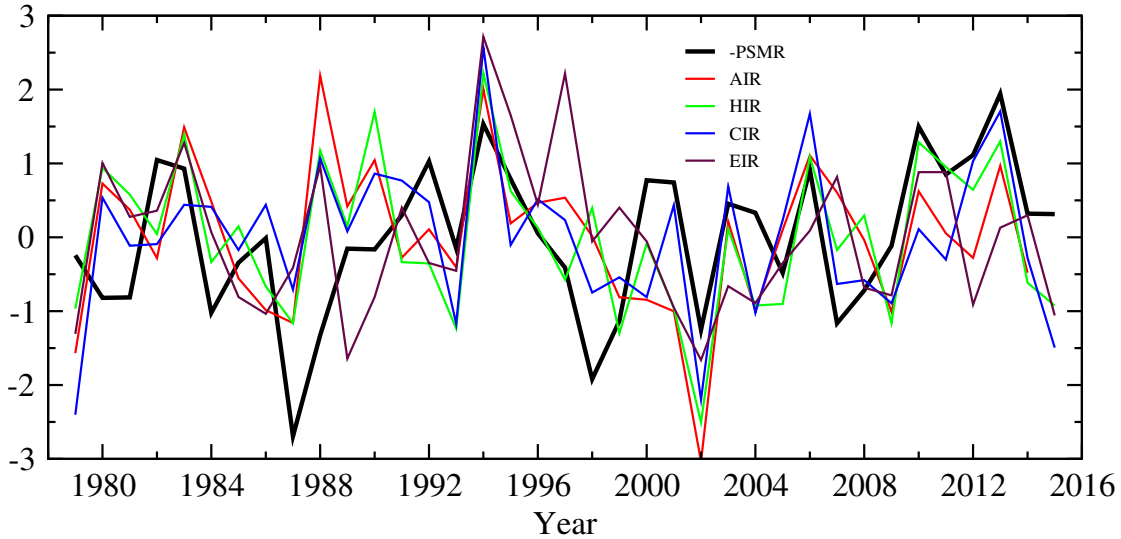

Fig. 4 a Monthly standard deviation of ATN (thick black line), PSMR (blue thick line) and their respective two boxes of north-west (thin green line), and north-east (thin red line) Indian region, b lead-lag correlation between PSMR and ATN from May to September (black curve) and simultaneous monthly CC between PSMR and ATN (dashed black curve), c time-series of PSMR (blue line) and ANPC (red line) for the period 1979-2015 expressed as standardized values of the seasonal (JA) 37-year normal (horizontal black lines are +1 and -1 standard deviation) and $\mathbf{d}$ comparison of inverse PSMR with different ISM indices. For panel, a ATN is considered only for positive Atlantic Niño years

averaged over the longitudes $0^{\circ}-30^{\circ} \mathrm{E}$ during the positive phase of Atlantic Niño (1998, Fig. 5c) and the negative phase of Atlantic Niño (1992, Fig. 5d). During positive phase the upper-level consecutive negative, positive, and negative pressure anomalies migrate meridionally toward higher latitudes, whereas during negative phase the upper-troposphere positive and negative pressure anomalies remains standing. During positive phase of Atlantic Niño, the ITCZ is very active associated with large-scale frequent deep convection, which produces strongest heating in the mid-to-upper troposphere. Such heating distribution leads to divergence in the upper troposphere resulting in vortex stretching. This pushes the GPH toward pole, generating stationary wave as observed during positive phase of Atlantic Niño year 1998. In the deep tropics, horizontal variations of GPH are much smaller, as it is difficult to maintain them in the presence of the weak Coriolis force, whereas in the mid-latitude/extra-tropics the GPH variations are much higher. During negative phase of Atlantic Niño (1992) the ITCZ was less active, which produced weak heating in the midto-upper troposphere. This had squash the upper-troposphere GPH toward tropics with anomalous negative and positive GPH along $35^{\circ} \mathrm{N}$ and $55^{\circ} \mathrm{N}$, respectively.

Response in AGCM and coupled model experiment It is shown from the observations that Atlantic Niño generates the upper troposphere meridional stationary wave modifying the GPH 
(o) Composite: positive ANPC \& excess PSMR



(c) 200-hPo GPH 1998

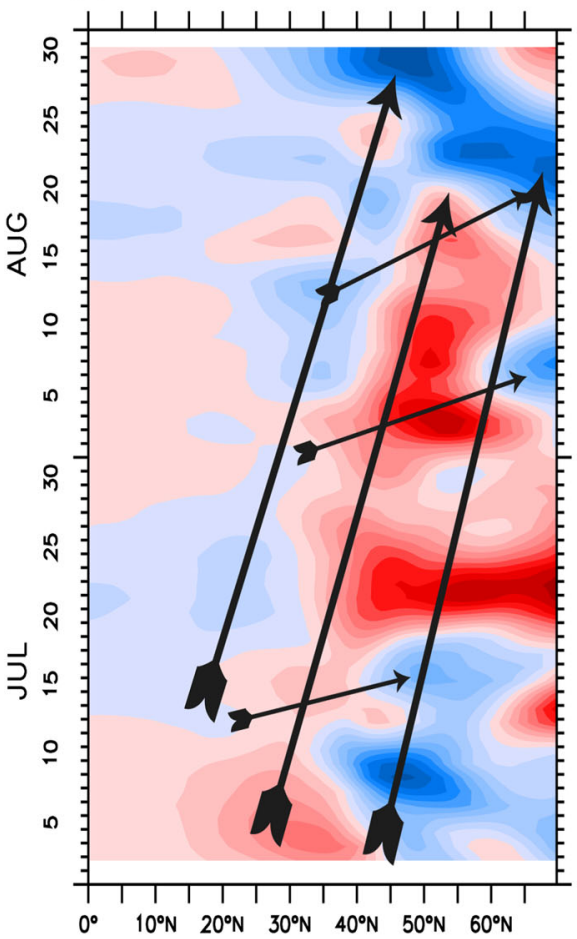

(d) 200-hPo GPH 1992



Fig. 5 a Composites of upper-level Rossby wave activity flux (vectors, $\mathrm{m}^{2} \mathrm{~s}^{-2}$ ), $200 \mathrm{hPa}$ zonal wind (shaded, $\mathrm{m} / \mathrm{s}$ ), and GPH anomalies (contours, $\mathrm{m}$ ) for positive ANPC and excess PSMR years, which are represented by filled circles in Fig. 4c $(1982,1983,1992$, and 1994), b same as a but for negative ANPC and deficient PSMR years, which are represented by filled squares in Fig. 4c $(1984,1987,1988,1998$, and 1999) and c, d hovmoller (latitude-time) plot for daily $200-\mathrm{hPa} \mathrm{GPH}$ anomalies averaged over the longitudes $0^{\circ}-30^{\circ} \mathrm{E}$ for the years 1998 and 1992 during JA

anomaly over north-west Europe. This alters the mid-latitude/ extratropical Eurasian Rossby wave and the Asian jet strength, which in turn influence the convective activity over India during peak phase of summer monsoon season. To confirm the importance of SST forcing in producing above discussed variations in mid-latitudinal circulation/wave dynamics, AGCM simulations forced with observed tropical $\mathrm{SST}^{38}$ are analyzed for the period of 1955-2001. Figure 6 shows CC of Atlantic Niño with 200 hPa GPH, zonal wind and precipitation in the model. It is found that the AGCM is able to capture the meridional stationary wave structure from north Africa to north-west Europe with some shift in GPH anomalies as compared with the reanalysis (Fig. 6a). Significant negative GPH CCS over north Africa, north-west Europe and significant positive CC over Mediterranean are apparent, discern the meridional stationary wave due to intense ITCZ. The significant positive CC over central Asia is the consequence of the Eurasian mid-latitude/extratropical zonally oriented Rossby wave train propagation from north-west Europe toward central Asia. The $200 \mathrm{hPa}$ GPH anomalies over Eurasian region with positive anomalies over north of Mediterranean and central Asia and negative anomaly over north-west Europe in response to Atlantic Niño is well represented by the Model. Weakening of the Asian jet strength south of Caspian Sea and associated precipitation anomaly dipole over Indian subcontinent with significant positive CC over north-east India and negative CC over north-west of India (shifted northward as compared with the observations) are seen in the model when correlated with Atlantic Niño index (Fig. $6 \mathrm{~b}, \mathrm{c}, \mathrm{d})$ in the model. The intense ITCZ is clearly visible over 
(a) Z200 (AddM)

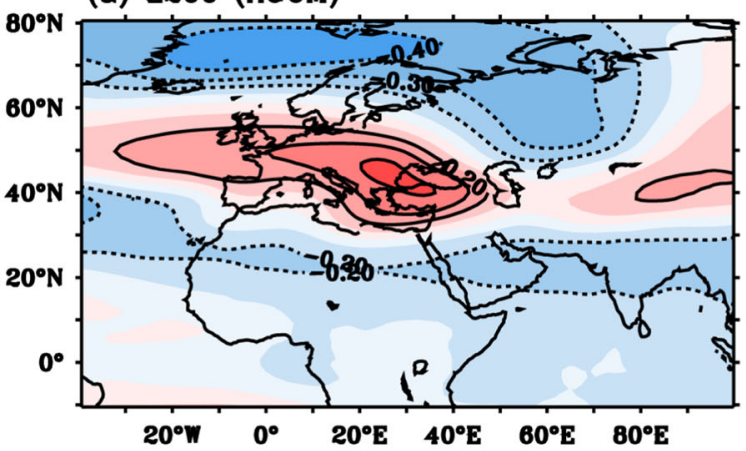

(c) Rainfall over ATN ITCZ (AGdM)

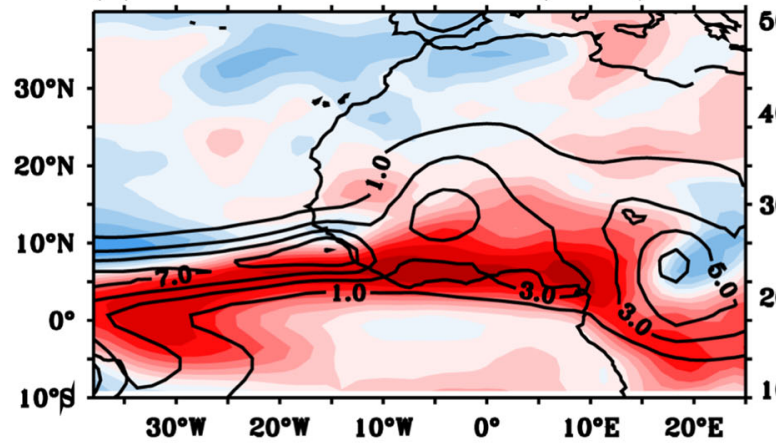

(b) U200 (AddM)

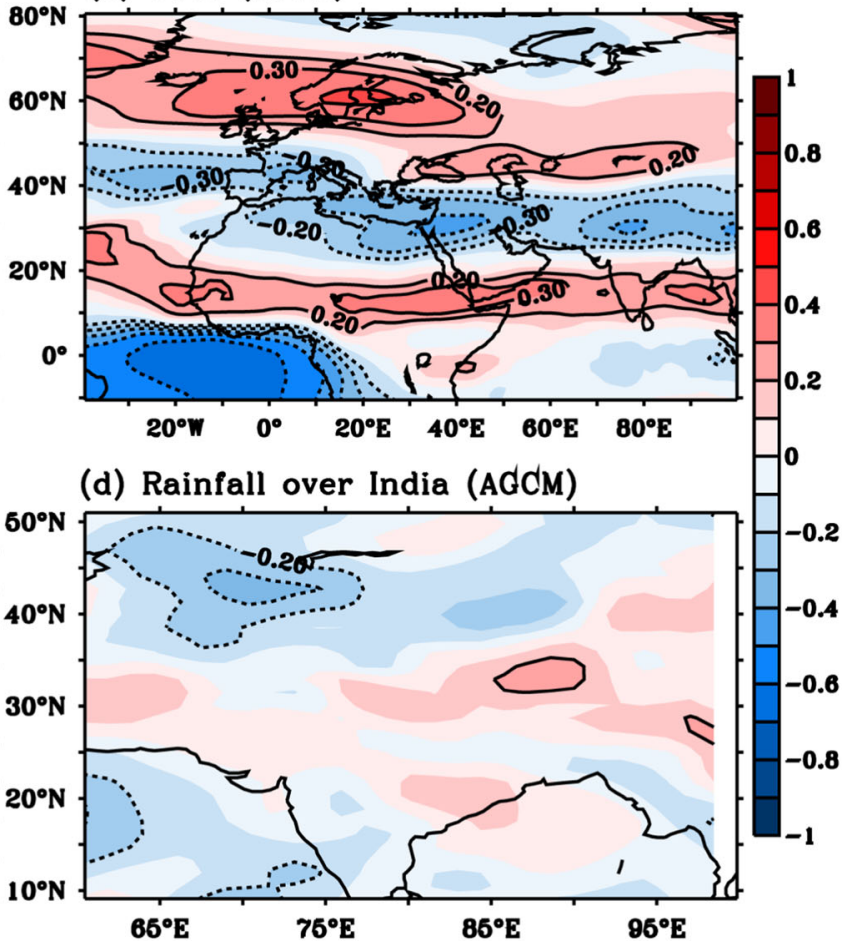

(g) daily Z200 (dddM exp)

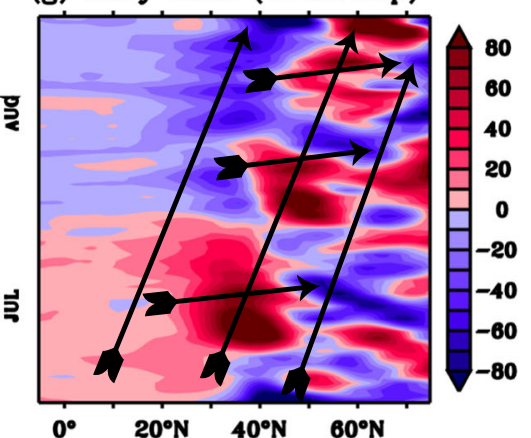

$0^{\circ} \quad 20^{\circ} \mathrm{N} \quad 40^{\circ} \mathrm{N} \quad 60^{\circ} \mathrm{N}$



(f) U200 (dddM exp)

Fig. 6 Correlation of ATN with anomalies of a $200 \mathrm{hPa}$ GPH (shaded), b $200 \mathrm{hPa}$ zonal wind (shaded), c equatorial Atlantic rainfall (shaded) and superimposed by precipitation climatology (ITCZ; contour, $\mathrm{mm} /$ day), and d rainfall over Indian monsoon region (shaded) in CAM3 atmospheric model, $\mathbf{e}, \mathbf{f}$ the difference between CFSv2 coupled model experiment (EXP) and control (CTRL) run $200 \mathrm{hPa}$ GPH (shaded, $\mathrm{m}$ ) and $200 \mathrm{hPa}$ zonal wind (shaded, $\mathrm{m} / \mathrm{s}$ ), and $\mathbf{g}$ hovmoller (latitude-time) plot for daily $200 \mathrm{hPa} \mathrm{GPH}$ anomalies averaged over longitudes $0^{\circ}-30^{\circ} \mathrm{E}$ in model experiment

Atlantic and Africa. Of note, that model shows overall shift in the atmospheric signals including precipitation. This AGCM result confirms that Atlantic Niño alters strength of the Asian jet by generating meridional stationary wave which in turn influence the mid-latitudinal wave dynamics with some uncertainty.

To further test this hypothesis, we have carried out idolized coupled model experiment by prescribing warm SST anomalies over the Atlantic Niño region in specific year 2001 (Fig. 6e, f) as discussed in Materials and methods. To isolate any effect of other SST forcing and extract only Atlantic Niño impact we have discussed the difference between experiment (EXP) and control (CTRL) fields. The model EXP clearly shows successive meridional negative, positive, negative, and positive GPH anomalies between tropics and extra-tropics over tropical Atlantic, north Africa, Europe, and north of Europe, respectively. This confirms that the Atlantic Niño (as the rest of globe SST kept same as in control run) warming generates the stationary wave meridionally. The successive zonal negative, positive, and negative GPH anomalies at $40^{\circ} \mathrm{N}$ over the Eurasian region are also visible, but not very strong. A mid-latitude/extratropical Eurasian Rossby wave train type feature is absent in this model unlike in the observations. In the Southern Hemisphere, the model EXP run has very well captured the atmospheric anomalies. In the Northern Hemisphere, the meridional stationary wave anomalies are slight shifted south compared with the observations. The $200 \mathrm{hPa}$ zonal wind shows the strong negative and positive anomalies over equatorial Atlantic and mid-latitude Atlantic in the Southern Hemisphere, respectively (Fig. $6 f$, b). In the Northern Hemisphere, the negative anomalies over north Africa is consistent with observations. The negative wind anomalies in the south of Mediterranean is slightly displaced southward owing to the southward shift in GPH anomaly. The negative zonal wind anomaly south of the positive 
GPH anomaly is well established by the model EXP. In the model EXP runs the Northern Hemisphere pressure anomalies are not strongly pushed poleward in the model as compared with the observations, which are not placed the $200 \mathrm{hPa}$ GPH anomalies at the right position (i.e., southward position than the observation). Figure $6 \mathrm{~g}$ shows model EXP daily $200 \mathrm{hPa}$ GPH anomalies averaged over $0^{\circ}-30^{\circ} \mathrm{E}$. It is apparently illustrates the meridional propagation GPH anomaly that confirms the Atlantic Niño warming generates the meridional stationary wave as seen in observations (Fig. 5c).

The mid-latitude/extratropical Eurasian Rossby wave train is very weak in the model to transverse the GPH anomaly from the north-west Europe downstream towards central/south Asia. It is important to note that many coupled models have low skill in predicting/reproducing mid-latitude wave pattern on seasonal time scale especially over the Asian jet region. ${ }^{39-41}$ Many World Climate Research Programme (WCRP) Coupled Model Intercomparison Project Phase 5 (CMIP5) 32 models are also not able to capture the northern extratropical wave train type features. ${ }^{33}$ Note that the model showed a poor skill in reproducing non-liner interaction between upper tropospheric standing waves and Rossby wave train over the north-west Europe region. Very weak central Asia GPH anomaly owing to weaker zonal wind anomalies toward the east of the Caspian Sea in CFSv2 experiment is consistent with many CMIP5 model results. Further, owing to very weak mid-latitude/extratropical Eurasian Rossby wave train associated with Atlantic Niño, the rainfall patterns over India land region are not well represented in this coupled model (figure not shown). Over all, despite having some limitations, the mode EXP run is able to represent the atmospheric adjustments associated with the Atlantic Niño as in the observations. This strongly supports our hypothesis that the Atlantic Niño could generate meridional stationary wave, which further influences the midlatitude wave pattern and Asian jet.

\section{DISCUSSION}

In this study, the influence of Atlantic Niño on ISM rainfall during boreal summer $(\mathrm{JA})$ is explored and proposed unraveling pathway. Both the ISM and Atlantic Niño, primarily peaks during boreal summer season. This study is of its first kind that shows the Atlantic Niño warming modulates the Asian jet through the wave train in mid-latitudes/extra-tropics. The Asian jet association with ISM rainfall variability have been discussed by several studies. ${ }^{29-32}$ The east-equatorial Atlantic cooling and ISM relationship has been documented. ${ }^{13,21-24}$ But none of these studies have shown the Atlantic Niño relationship with ISM through the Asian jet. This study shows that the anomalous east-west dipole pattern in JA rainfall in north India is highly correlated with Atlantic Niño. The observed analysis revealed that positive Atlantic Niño caused for intensification of the ITCZ, which enhances the upper-troposphere divergence and pushes the GPH poleward. This generates the meridional stationary wave with successive negative, positive, and negative GPH anomalies over tropical Africa, Mediterranean, and north-west Europe, respectively. This is further confirmed by the coupled model experiment. The anomalous GPH anomaly over north-west Europe acts as center of action for the propagation/ initiation of zonally oriented mid-latitude/extratropical Rossby wave train over the Eurasian region, which reinforce positive GPH anomaly over central Asia. This positive GPH anomaly weakens the Asian jet toward the east of the Caspian Sea. The negative relative vorticity formed south of the Asian jet streak gets reduced, thereby reduction in the upper-troposphere divergence, which subdues the monsoon activity over Indian region and vice-versa for the negative Atlantic Niño event.

The hypothesis has been supported by AGCM simulations and coupled model experiment. Recently, the operational forecasts show poor skill in predicting ISM rainfall in the recent decade, which is owing to lack of new predictive information. ${ }^{42}$ Therefore, bringing out new pathways and sources of ISM rainfall variability is essential. The present study suggests monitoring of Atlantic Niño evolution and adjustments in the mid-latitudes circulation would be useful elements to be considered for predictability.

\section{MATERIALS AND METHODS}

The SST, $250 \mathrm{hPa} \mathrm{GPH}$, and $850 \mathrm{hPa}$ and $250 \mathrm{hPa} \mathrm{U}$ and $\mathrm{V}$ wind for the period 1979-2015 are obtained from the European Center for MediumRange Weather Forecasts ERA-Interim reanalysis data set at $0.75^{\circ}$ spatial resolution. ${ }^{43}$ For rainfall over Indian landmass, the monthly gridded rainfall at $0.25^{\circ} \times 0.25^{\circ}$ resolutions for the period $1979-2015$ is used from the Indian Meteorological Department. ${ }^{44}$ Further, GPCP (Global Precipitation Climatology Project) monthly data set at a resolution of $2.5^{\circ}$ is used in the current study.

The summer season is defined as the average of July and August (JA) and is used throughout this study as ISM rainfall peaks in these months. A total of 37-year, JA boreal summer season from 1979 to 2015 has been considered for this study. EOF analysis is performed on the de-trended JA seasonal gridded SST comprising regions of tropical Atlantic $\left(50^{\circ} \mathrm{W}-15^{\circ} \mathrm{E}\right.$, $20^{\circ} \mathrm{S}-10^{\circ} \mathrm{N}$ ) to study the interannual variability of the dominant mode of Atlantic Niño. Other methods used are simultaneous correlation and regression on the de-trended datasets. The excess and deficient years are defined if the standardized values (i.e., the mean subtracted and divided by the standard deviation) are greater than or near to +1 and less than or near to -1 , respectively of PSMR index. The Rossby wave activity fluxes ${ }^{28}$ have been calculated to show the existence and propagation of the Rossby wave in the mean flow.

To test our hypothesis that the Atlantic Niño influence ISM through Asian jet, we have analyzed atmospheric general circulation model (AGCM) simulations forced with observed SSTs. An AGCM used in this study is the National Center for Atmospheric Research (NCAR) Community Atmospheric Model version 3 (CAM3), ${ }^{45}$ which is Tropical Ocean Global Atmosphere (TOGA), forced by tropical $\left(20^{\circ} \mathrm{N}-20^{\circ} \mathrm{S}\right)$ interannual observed SSTs from 1871 to 2001 and last 50 years run is used in the current study. Outside the tropics, climatological monthly SSTs are prescribed, with a linear transition between $20^{\circ}$ and $30^{\circ}$. The horizontal resolution of the model is T85, equivalent to $1.4^{\circ}$ latitude and $1.4^{\circ}$ longitude. As five member ensemble mean and model output is obtained from http://www.cesm.ucar. edu/working_groups/Variability/experiments.html.

Further, we have carried out a coupled model sensitivity experiment using the National Centers for Environmental Prediction (NCEP) Climate Forecast System version -2 (CFSv2). ${ }^{46}$ NCEP-CFSv2 is the fully coupled ocean-atmosphere model with advanced physics. Retrospective forecast (hindcast) is prepared for 9 months covering a period of 30 years from 1985 to 2015 based on CFSv2 at Indian Institute of Tropical Meteorology. The atmospheric initial conditions are obtained from the NCEP Reanalysis (R2) data. The ocean initial conditions are obtained from the NCEP Global Ocean Data Assimilation System. Retrospective forecast starts from a specific month May, there are 10 atmospheric initial conditions (10 ensemble members), which are partitioned into two segments. In the present study, we have used the 10 ensemble member mean for analysis and run is referred as control run (CTL). In the experiment (EXP-1) we have prescribed strong warming over the Atlantic Niño region. This experiment is carried out for the specific year 2001, which is normal year (no ENSO or Atlantic Niño). The model is initialized in May and run for 9 months by prescribing Atlantic Niño like pattern SST. Difference between EXP and CTL is analyzed and discussed.

\section{Data availability}

The IMD gridded data are obtained by writing email to ncc@imd.gov.in and the reanalysis data sets are downloaded from their respective websites. The model data used in this study are available from the contributing author JSC on request.

\section{ACKNOWLEDGEMENTS}

We acknowledge Director, ESSO-IITM for support. The data have been taken from Web sites and all data sources are duly acknowledged. We thank the anonymous reviewers for the comments that helped us to improve the manuscript. Computational and graphical analyses required for this study have been completed with the free software xmgrace, NCL and Ferret. We thank Yuko Okumura (University of Texas 
Institute for Geophysics) and CESM (Community Earth System Model) Climate Variability Working Group for making the CAM3 TOGA simulations available.

\section{AUTHOR CONTRIBUTIONS}

R.K.Y conceived the study. G.S and J.S performed model experiments and analysis. R. K.Y wrote the initial manuscript. All authors contributed to interpreting results, discussion of the associated dynamics, and improvement of this paper.

\section{ADDITIONAL INFORMATION}

Competing interests: The authors declare no competing interests.

Publisher's note Springer Nature remains neutral with regard to jurisdictional claims in published maps and institutional affiliations.

\section{REFERENCES}

1. Goswami, B. N. South Asian summer monsoon. Intraseasonal Variability of the Atmosphere-Ocean Climate System. (eds W. K. M. Lau \& D. E. Waliser) pp 19-62 (Springer, 2005).

2. Parthasarathy, B., Munot, A. A. \& Kothawale, D. R. All-India monthly and seasonal rainfall series 1871-1993. Theor. Appl. Clim. 49, 217-224 (1994).

3. Saha, K. R., Mooley, D. A. \& Saha, S. The Indian monsoon and its economic impact. Geo. J. 3, 171-178 (1979)

4. Li, G., Xie, S.-P., He, C. \& Chen, Z. Western Pacific emergent constraint lowers projected increase in Indian summer monsoon rainfall. Nat. Clim. Change 7, 708-712 (2017).

5. Zebiak, S. E. Air-sea interaction in the equatorial Atlantic region. J. Clim. 6, 1567-1586 (1993).

6. Lübbecke, J. F. \& McPhaden, M. J. Symmetry of the Atlantic Niño mode. Geophys. Res. Lett. 44, 965-973 (2017).

7. Lübbecke, J. F. \& McPhaden, M. J. A comparative stability analysis of Atlantic and Pacific Niño modes. J. Clim. 26, 5965-5980 (2013).

8. Carton, J. A. et al. Decadal and interannual SST variability in the tropical Atlantic Ocean. J. Phys. Oceanogr. 26, 1165-1175 (1996).

9. Bjerknes, J. Atmospheric teleconnections, from the equatorial Pacific. Mon. Wea. Rev. 97, 163-172 (1969).

10. Carton, J. A. \& Huang, B. Warm events in the tropical Atlantic. J. Phys. Oceanogr. 24, 888-903 (1994).

11. Richter, l. et al. Multiple causes of interannual sea surface temperature variability in the equatorial Atlantic ocean. Nat. Geosci. 6, 43-47 (2013).

12. Nnamchi, H. C. et al. Thermodynamic controls of the Atlantic Niño. Nat. Commun. 6, 8895 (2015)

13. Yadav, R. K. On the relationship between east equatorialAtlantic SST and ISM through Eurasian wave. Clim. Dyn. 48, 281-295 (2017).

14. Janicot, S., Harzallah, A., Fontaine, B. \& Moron, V. West African monsoon dynamics and eastern equatorial Atlantic and Pacific SST Anomalies. J. Clim. 11, 1874-1882 (1998).

15. Nobre, P. \& Shukla, J. Variations of sea surface temperature, wind stress, and rainfall over the tropical Atlantic and South America. J. Clim. 9, 2464-2479 (1996).

16. Mitchell, T. P. \& Wallace, J. M. The annual cycle in equatorial convection and sea surface temperature. J. Clim. 5, 1140-1156 (1992).

17. Li, T. \& Philander, S. G. H. On the seasonal cycle of the equatorial Atlantic Ocean. J. Clim. 10, 813-817 (1997).

18. Chang, P., Ji, L. \& Li, H. A decadal climate variation in the tropical Atlantic Ocean from thermodynamic air-sea interactions. Nature 385, 516-518 (1997).

19. Chang, P. et al. The effect of local sea surface temperatures on atmospheric circulation over the tropical Atlantic sector. J. Clim. 13, 2195-2216 (2000).

20. Huang, B. et al. The ENSO effect on the tropical Atlantic variability: a regionally coupled model study. Geophys. Res. Lett. 29, 2039 (2002).

21. Kucharski, F. et al. Low-frequency variability of the Indian monsoon-ENSO relationship and the tropical Atlantic: the 'weakening' of the 1980s and 1990s. J. Clim. 20, 4255-4266 (2007)

22. Kucharski, F. et al. A Gill-Matsuno-type mechanism explains the tropical Atlantic influence on African and Indian monsoon rainfall. Q. J. R. Meteorol. Soc. 135, 569-579 (2009).

23. Kucharski, F. et al. Atlantic forced component of the Indian monsoon interannual variability. Geophys. Res. Lett., 35, L04706 (2008).https://doi.org/10.1029/ 2007GL033037.
24. Barimalala, R., Bracco, A. \& Kucharski, F. The representation of the South The tropical Atlantic teleconnection to the Indian Ocean in the AR4 coupled models. Clim. Dyn. 38, 1147-1166 (2012).

25. Gill, A. E. Some simple solutions for heat-induced tropical circulations. Q. J. $R$. Meteorol. Soc. 106, 447-462 (1980).

26. Matsuno, T. Quasi-geostrophic motions in the equatorial area. J. Meteorol. Soc. Jpn 44, 25-43 (1966).

27. Nnamchi, H. C., Li, J. P., Kucharski, F., Kang, I.-S., Keenlyside, N. S., Chang, P. \& Farneti, R. An equatorial-extratropical dipole structure of the Atlantic Nĩno. J. Clim. 29, 7295-7311 (2016).

28. Takaya, K. \& Nakamura, H. A formulation of a phase-independent wave-activity flux for stationary and migratory quasigeostrophic eddies on a zonally varying basic flow. J. Atmos. Sci. 58(6), 608-627 (2001)

29. Enomoto, T., Hoskin, B. J. \& Matsuda, Y. The formation mechanism of the Bonin high in August. Q. J. R. Meteorol. Soc. 129, 157-178 (2003).

30. Lu, R.-Y., Oh, J.-H. \& Kim, B.-J. A teleconnection patternin upper-level meridional wind over the North African and Eurasian continent in summer. Tellus 54A, 44-55 (2002).

31. Wang, L., Xu, P., Chen, W. \& Liu, Y. Interdecadal variations of the Silk Road pattern. J. Clim. 30, 9915-9932 (2017).

32. Yadav, R. K. Mid-latitude Rossby wave modulation of the Indian summer monsoon. Q. J. R. Meteorol. Soc. 143, 2260-2271 (2017).

33. Kucharski, F. \& Joshi, M. K. Influence of tropical South Atlantic sea-surface temperatures on the Indian summer monsoon in CMIP5 models. Q. J. R. Meteorol. Soc. 143, 1351-1363 (2017).

34. Ding, Q. \& Wang, B. Intraseasonal teleconnection between the summer Eurasian wave train and the Indian Monsoon. J. Clim. 20, 3751-3767 (2007).

35. Ding, Q. \& Wang, B. Circumglobal Teleconnection in the Northern Hemisphere Summer. J. Clim. 18, 3483-3505 (2005).

36. Goswami, B. N., Krishnamurthy, V. \& Annamalai, H. A broad-scale circulation index for the interannual variability of the Indian summer monsoon. Q. J. R. Meterol. Soc. 125, 611-633 (1999).

37. Goswami, B. N., Venugopal, V., Sengupta, D., Madhusoodanan, M. S. \& Prince, K. X Increasing trend of extreme rain events over India in a warming environment. Science 314, 1442-1445 (2006).

38. Hurrell, J. W., Kushnir, Y., Ottersen, G. \& Visbeck, M. An overview of the North Atlantic Oscillation. The North Atlantic Oscillation: Climatic Significance and Environmental Impact, Geophys. Monogr. 1-35 (2003).

39. Lee, J.-Y. et al. How predictable is the Northern Hemisphere summer uppertropospheric circulation? Clim. Dyn. 37, 1189-1203 (2011).

40. Kosaka, Y. et al. Limitations of seasonal predictability for summer climate over East Asia and the Northwestern Pacific. J. Clim. 25, 7574-7589 (2012).

41. Chowdary, J. S. et al. Seasonal prediction of distinct climate anomalies in summer 2010 over the tropical Indian Ocean and SouthAsia. . J. Meteor. Soc. Jpn. 92, 1-16 (2014).

42. Wang, B. et al. Rethinking Indian monsoon rainfall prediction in the context of recent global warming. Nat. Commun. 6, 7154 (2015).

43. Dee, D. P. et al. The ERA-Interim reanalysis: configuration and performance of the data assimilation system. Q. J. R. Meteorol. Soc. 137, 553-597 (2011).

44. Pai, D. S. et al. Analysis of the daily rainfall events over India using a new long period $(1901-2010)$ high resolution $\left(0.25^{\circ} \times 0.25^{\circ}\right)$ gridded rainfall dataset. Clim. Dyn. 45, 755-776 (2015).

45. Collins, W. D. et al. The community climate system model version 3 (CCSM3). J. Clim. 19, 2122-2143 (2006).

46. Saha, S. et al. The NCEP climate forecast system version 2. J. Clim. 27, 2185-2208 (2014).

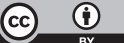

Open Access This article is licensed under a Creative Commons Attribution 4.0 International License, which permits use, sharing, adaptation, distribution and reproduction in any medium or format, as long as you give appropriate credit to the original author(s) and the source, provide a link to the Creative Commons license, and indicate if changes were made. The images or other third party material in this article are included in the article's Creative Commons license, unless indicated otherwise in a credit line to the material. If material is not included in the article's Creative Commons license and your intended use is not permitted by statutory regulation or exceeds the permitted use, you will need to obtain permission directly from the copyright holder. To view a copy of this license, visit http://creativecommons. org/licenses/by/4.0/.

(c) The Author(s) 2018 